\title{
Multidisciplinary residential home intervention to improve outcomes for frail residents
}

\author{
Anna Steel ${ }^{1 *} \mathbb{D}$, Helen Hopwood ${ }^{2}$, Elizabeth Goodwin ${ }^{3}$ and Elizabeth L. Sampson ${ }^{2,4}$
}

\begin{abstract}
Background: Residential homes provide accommodation and assistance with personal care only and are not required to have registered nurses on site. However, their residents often have a combination of comorbidity, polypharmacy, frailty and mental-health conditions with poor access to healthcare to meet these needs. Integrated healthcare for older people is a key NHS priority in the Long-Term Plan and the Five-Year Forward View. We describe development and implementation of multi-disciplinary intervention to integrate healthcare and promote interprofessional education.

Methods: A multi-disciplinary residential home quality improvement project in two cycles by a team comprising senior and trainee general practitioners, trainees in geriatrics, psychiatry, pharmacist and residential home senior staff. The intervention was underpinned by the framework for enhanced health in care homes including Comprehensive Geriatric Assessment (CGA) and mental-health review. Each intervention session included an educational presentation by a team member consideration of each resident in a pre-evaluation multi-disciplinary discussion followed by a structured clinical assessment and discussion of proposed management.
\end{abstract}

Results: Three residential homes participated with a total 34 residents receiving intervention. In one residential home, there was a $75 \%$ reduction in admissions for those reviewed and a reduction in overall admission costs. Polypharmacy was reduced by an average of 2 medications per resident across the three sites. There was a $63 \%$ increase in cardio-pulmonary resuscitation decisions and $76 \%$ increase in advance care planning discussions.

Conclusion: This was an effective model for multi-disciplinary trainees working with a perceived impact on physical and mental health, and valuable opportunities for sharing learning.

Keywords: Interdisciplinary, Long-term care, Geriatric assessment, Mental-health

\section{Background}

Approximately 420,000 older people live in care homes in England [1]. "Care homes" is a generic term; within the UK there are "care homes with nursing" and "residential homes" (RHs) providing accommodation and support with activities of daily living, but without on-site nurses.

*Correspondence: annasteel@nhs.net

${ }^{1}$ Barnet Hospital, Wellhouse Lane, Barnet EN5 3DJ, UK

Full list of author information is available at the end of the article
Resident needs in both nursing and RHs are complex, with a combination of physical frailty and mental health conditions [2].

Care home residents have $40-50 \%$ more emergency admissions and fewer outpatient appointments than the general population of the same age [3]. Many avoidable admissions are driven by unsatisfactory provision of healthcare services $[4,5]$ with medication errors occurring in approximately $70 \%$ of residents [6]. The majority of care home residents are in their last years of life [3] but 
may not receive adequate end-of-life care or advance care planning (ACP) [7]. This is especially challenging for the $80 \%$ of the care home population with dementia [8].

Enhanced Health in Care Homes (EHCH) is a cornerstone of the NHS Long Term Plan [9]. Integrated care between primary, secondary and community providers, is effective and can lower rates of emergency bed use [3, 10]. Multi-disciplinary teams (MDTs) linking community and hospital-based services increase functioning, reduce hospital costs and lengths of stay [11]. Key Recommendations from The British Geriatrics Society (BGS) Quest for Quality report include ensuring fair access to NHS services, providing a comprehensive geriatric assessment (CGA), promoting autonomy and care plans towards the end-of-life [5]. Despite many "top down" policy drivers, implementing change in practice is challenging and a more "bottom-up" context-specific approach such as local quality improvement may deliver more pragmatic and sustainable change [11]. The strength of a quality improvement approach includes linking useful interventions with improvement results and why they worked, which may be able to inform improvement elsewhere [12].. The process of healthcare improvement is about bridging gaps within the six domains of healthcare quality as set out by the Institute of Medicine: safety, effectiveness, patient-centred, timely, efficiency and equity [13].

RHs have higher ambulance call and emergency admission rates $[3,14]$ and fewer General Practitioner (GP) visits [15] compared to care homes with nursing thus our focus on RHs for this project.

We aimed to address a range of important clinical issues to improve multi-disciplinary care in RHs focusing on key elements derived from current policy; CGA, medication optimisation, end-of-life care planning and education to reduce hospital admissions [16].

\section{Methods}

We conducted a multi-disciplinary RH quality improvement project in two cycles. The first cycle was a pilot, subsequently rolled out to another location. Cycle one was conducted between 20/09/2017-14/02/2018 and cycle two between 21/03/2018-12/08/2018.

\section{Context}

The project was set within three urban RHs in North London. The first cycle was conducted in RHs 1 and 2 and the second cycle in RH 3 . The general practice supporting homes 1 and 2 had five GP partners and two salaried GPs looking after 10,500 patients, 125 of whom were in three different RHs. The GP supporting RH 3 worked in a practice with two partners, four salaried GPs and 9000 patients, 40 of whom resided in one RH.
We collected data on RH characteristics; location, type of care, number of beds, Care Quality Commission (CQC) rating,

\section{Intervention team}

Cycle one: The team included a GP lead, senior trainees from GP (one), psychiatry (one) and geriatrics (two), a primary-care pharmacist, the $\mathrm{RH}$ manager (homes 1 and 2 ) and deputy manager (home 1).

Cycle two: The team included a GP partner, senior trainees from GP (three), psychiatry (one) and geriatrics (three), primary-care pharmacists and the RH manager.

\section{Intervention}

The project was underpinned by the $\mathrm{EHCH}$ implementation framework [16] includes seven key standards; enhanced primary care support, multi-disciplinary support, high quality end-of-life care and dementia care, joined-up commissioning and collaboration between health and social care and workforce development. The $\mathrm{EHCH}$ model aims to implement these care elements in a coordinated sustainable way to deliver person centred care. These standards informed the session design which was further adapted for cycle 2 based on the change in setting and learning from cycle 1.

\section{Cycle 1}

MDT reviews were held in the RH (Fig. 1). Residents whose physical or mental health caused concern raised by care home staff or following GP review were identified in advance and families were invited to attend. Team members obtained medical records in advance. Sessions lasted $3 \mathrm{~h}$. Pre-evaluation MDT discussion was followed by clinical assessment. The team divided into smaller groups to review residents according to whether there was a geriatric, psychiatric or general medical focus. The team re-convened to discuss proposed management, including medication review and identified an educational topic for the following session based on predominant issues. Following sessions, GPs made any treatment changes, organised follow-up and held resuscitation and ACP discussions with families. Psychiatric follow-up occurred where necessary.

\section{Cycle 2}

In cycle 2, a GP trainee took over the lead role to encourage trainee leadership. The team expanded to include more members ensuring there was at least one member from each discipline in each session.

\section{Outcomes}

To assess intervention impact, we collected data relating to the project aims as defined by the $\mathrm{EHCH}$ framework; 


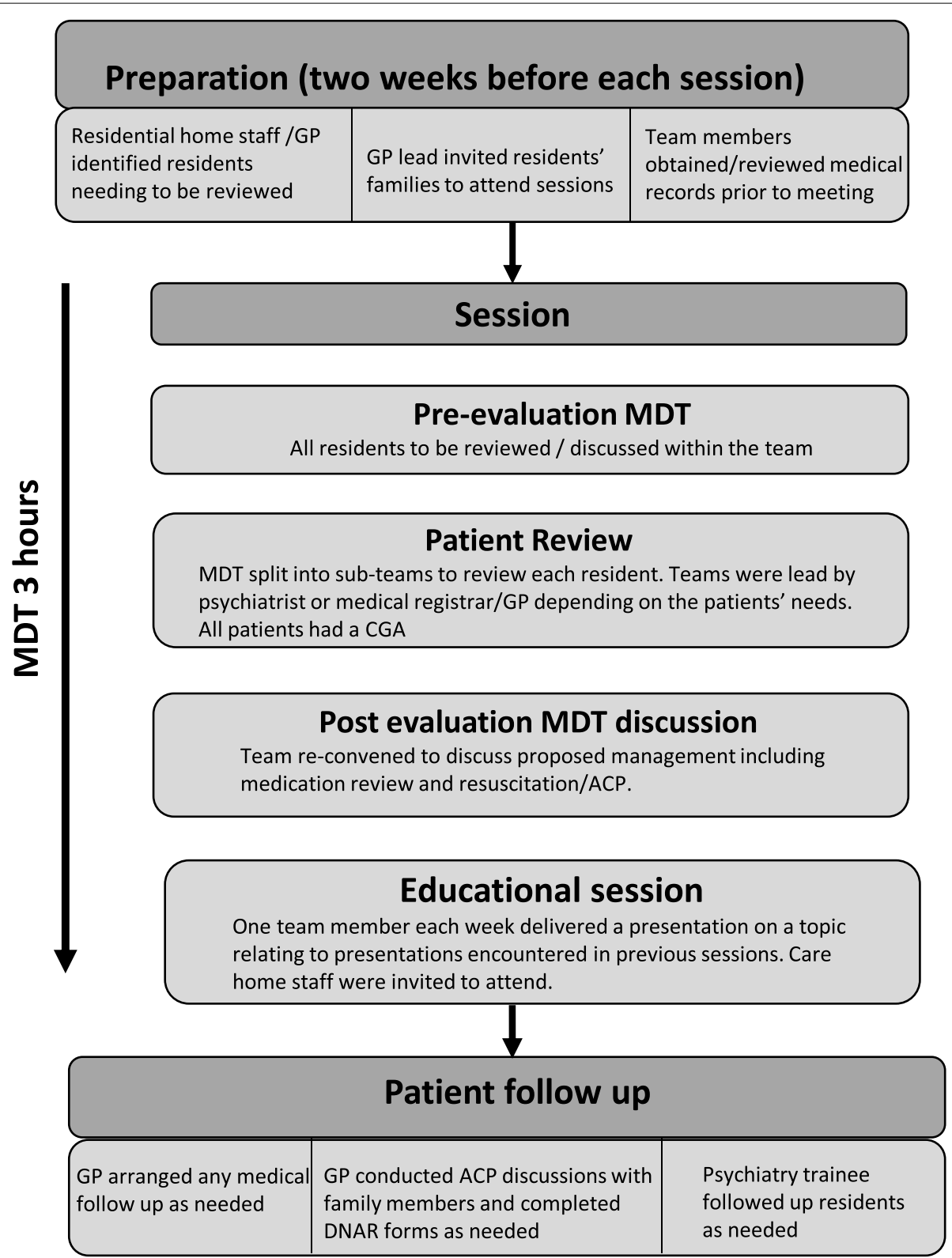

Fig. 1 Design for each monthly session

CGA, polypharmacy, end-of-life care and education. Outcome measures were reviewed following cycle 1 and some were adapted for cycle 2 . To ensure data collection was complete, we had full access to all GP and RH records. We monitored the local health and social care economy for any other initiatives or changes in service provision which may have impacted our project.

\section{Individual resident level data}

We collected data on demographics including age, gender and clinical factors including number and type of medications [17] (but not classification at the time of being assessed), physical and psychiatric comorbidities as documented for each patient on the NHS summary care record (this is a list of comorbidities held for each patient in UK primary care) and Clinical Frailty Scale (CFS). The CFS has established reliability and validity [18] and helps identify patients with severe frailty to trigger appropriate interventions such as advance 
care planning. The CFS ranges from 1-being very fit to 9-being terminally ill. We documented whether participants had capacity to decide about the treatment plan.

\section{System level data}

We collected data from GP records on the number of hospital admissions from the $\mathrm{RH}$ (in cycle 1 admission data were collected during the project only and in cycle 2 admission data were collected in the 12 months prior, during and 12 months after the project). Costs of acute admissions for the whole RH were obtained for cycle 2 from the CCG, calculated using Healthcare Resource Groups. These are standard groupings of clinically similar treatments which use common levels of healthcare resource. This is a validated method to determine fair and equitable reimbursement for healthcare services in the UK [19].

\section{Process measures}

In cycle 1, feedback from participating teams was gathered independently by an education group formed by Health Education England (HEE) and University College London Partners (UCLP). Educational sessions were assessed by documenting the topics, number of attendees, RH staff feedback via questionnaire (cycle 2 only), and participant feedback (in cycle 1 feedback was from HEE and UCLP and in cycle 2 feedback was via questionnaire). We monitored return rates of questionnaires.

\section{Data analysis}

This was a quality improvement project we therefore used simple descriptive statistics for data collected. For example, mean age of participants, number of medications, number of comorbidities were described with mean and range. Simple percentages were used to described outcome data such as advance care plans and number of DNACPR forms. We calculated the mean session rating based on MDT feedback. We also extracted qualitative data using comments from the MDT feedback forms.

\section{Ethical considerations}

This was a quality improvement project, sponsored by HEE and UCLP who are part of the Academic Health Science Networks; driving adoption and spread of innovation across healthcare. The project was led by local GPs and was an enhancement of their usual service. The implementation of the project was monitored by HEE. Staff were given the option of whether they wished to complete questionnaires or not.

\section{Results}

The RHs ranged between 21 and 73 beds (Table 1 ). Tables 1 and 2 show resident demographics and outcomes.

\section{Cycle 1}

\section{Process}

A total of 13 residents were assessed across seven sessions; 5 males and 8 females, mean 82.5 years old; mean number comorbidities 8.2 ; mean number medications 8.6, mean clinical frailty score 6.5 (moderately frail) (Table 1$)$. Only $1(11 \%)$ resident had mental capacity (determined by the 2005 Mental Capacity Act) [20] to engage in discussion about their treatment plans. For the remainder, plans were made in best interests. No residents declined to participate or dropped out of the project, i.e. through change of residence.

\section{CGA}

All 13 residents had a CGA with psychiatric input and 11 (85\%) had confirmed diagnosis of dementia; 7 (54\%) with behavioural and psychological symptoms of dementia (BPSD) or a secondary psychiatric problem. Of those with BPSD, 4 (57\%) (according to staff) or 5 (71\%) (according to families) improved from the point of intervention over the subsequent 6 months. Three residents had acute medical issues addressed, potentially avoiding hospital admissions; urinary tract infection, chronic obstructive pulmonary disease exacerbation and fluid overload. One resident required urgent admission. No other residents were admitted during the project's course.

\section{Polypharmacy}

Reviews resulted in an overall reduction of -0.8 medications per resident. This was achieved using STOPP START criteria [21] and checking anticholinergic burden.

\section{End of life care plans}

Families were unable to attend for all but one resident. A total of 10 separate ACP discussions were held by GPs with families, triggered by the MDT. All residents were suitable for Do Not Attempt Cardio-Pulmonary Resuscitation (DNACPR) and ACP; 8 were newly initiated. ACPs are now coded as a 'significant problem' in the GP summary care record ensuring it is easily visible in the main section of the summary.

\section{Education}

A total of 7 half-hour educational sessions were delivered (Table 2). We took a participatory approach and 
Table 1 Care home and resident demographics

\begin{tabular}{|c|c|c|c|}
\hline & \multicolumn{2}{|l|}{ Cycle 1} & \multirow{2}{*}{$\begin{array}{l}\text { Cycle } 2 \\
\text { Care Home } 3\end{array}$} \\
\hline & Care Home 1 & Care Home 2 & \\
\hline Location & North London (urban) & North London (urban) & North London (urban) \\
\hline Type of care & Residential & Residential & Residential \\
\hline Beds & 21 & 35 & 73 \\
\hline Care Quality Commission (CQC) rating (date of inspection) & $\begin{array}{l}\text { 'Good' } \\
\text { (July 2017) }\end{array}$ & $\begin{array}{l}\text { 'Good' } \\
\text { (October 2017) }\end{array}$ & $\begin{array}{l}\text { 'Inadequate' } \\
\text { (December 2018) }\end{array}$ \\
\hline \multirow[t]{2}{*}{ Number of sessions held } & 5 & 2 & 10 \\
\hline & s Sept 2017 - Jan 2018 & Nov 2017 - Feb 2018 & March 2019 - Dec 2019 \\
\hline Number of residents assessed & 9 & 4 & 21 \\
\hline Mean age (range) & $\begin{array}{l}82.1 \\
(62-95)\end{array}$ & $\begin{array}{l}80.8 \\
(78-84)\end{array}$ & $\begin{array}{l}86.4 \\
(77-97)\end{array}$ \\
\hline Male: female & $5: 4$ & $0: 4$ & $11: 10$ \\
\hline Mean number of medications (range) & $\begin{array}{l}9.0 \\
(4-18)\end{array}$ & $\begin{array}{l}10.0 \\
(5-12)\end{array}$ & $\begin{array}{l}7.1 \\
(2-18)\end{array}$ \\
\hline Mean number of comorbidities excluding dementia (range) & $\begin{array}{l}7.8 \\
(4-13)\end{array}$ & $\begin{array}{l}9.3 \\
(6-15)\end{array}$ & $\begin{array}{l}6.7 \\
(3-16)\end{array}$ \\
\hline $\begin{array}{l}\text { Number with pre-recorded dementia diagnosis (\% of total participating } \\
\text { residents) }\end{array}$ & $\begin{array}{l}7 \\
(77.8 \%)\end{array}$ & $\begin{array}{l}4 \\
(100 \%)\end{array}$ & $\begin{array}{l}16 \\
(76.2 \%)\end{array}$ \\
\hline $\begin{array}{l}\text { Number of new diagnoses of dementia made during intervention (\% of total } \\
\text { participating residents) }\end{array}$ & $\begin{array}{l}0 \\
(0 \%)\end{array}$ & $\begin{array}{l}0 \\
(0 \%)\end{array}$ & 0 \\
\hline Number of residents with BPSD (\% of participating residents with dementia) & $\begin{array}{l}3 \\
(42.9 \%)\end{array}$ & $\begin{array}{l}4 \\
(100 \%)\end{array}$ & $\begin{array}{l}16 \\
(100 \%)\end{array}$ \\
\hline Mean clinical frailty score (range) & $\begin{array}{l}6.6 \\
(6-8)\end{array}$ & $\begin{array}{l}6.0 \\
(5-7)\end{array}$ & $\begin{array}{l}7.3 \\
(6-9)\end{array}$ \\
\hline $\begin{array}{l}\text { Number with capacity to decide about the treatment plan (\% of total partici- } \\
\text { pating residents) }\end{array}$ & $\begin{array}{l}1 \\
(11.1 \%)\end{array}$ & $\begin{array}{l}0 \\
(0 \%)\end{array}$ & $\begin{array}{l}4 \\
(19.0 \%)\end{array}$ \\
\hline
\end{tabular}

the topics were decided collectively by the MDT based on interesting cases the previous week and areas of education felt to be needed by the team.

\section{Learning and adaptation from cycle 1}

After cycle 1 the multidisciplinary group met to review all 13 cases focusing on the interventions made, the outcomes, the end-of-life care plans and the feedback from the educational sessions. We reflected on the barriers and facilitators to our achieving our objectives. From cycle 1 we understood the value of making decisions as a team and inter-professional learning, so continued this model in cycle 2. To promote the training aspect of the project, the GP trainee was the team lead in cycle 2. Trying to cover two RHs was difficult and reduced continuity. We therefore focused on one home for cycle 2. In cycle 1 relatives were mostly unable to come to meetings so we did not set this as a priority, rather we highlighted those needing further discussion. The educational value of the sessions was more apparent after cycle 1 and so medical, pharmacy and other students were invited to attend. Unlike in cycle 1 , data on BPSD was not collected in cycle 2 as it was not central to our aims but we did include hospital admission data pre and post project. We also gathered data on electronic 'Coordinate my Care' (CMC) records created in cycle 2 as a result of learning in cycle 1. $\mathrm{CMC}$ is a London-wide online platform to share advance care planning information between healthcare providers.

\section{Cycle 2}

\section{Process}

A total of 21 residents were assessed in ten sessions, (11 males and 10 females, mean age 86.4 years old; mean number comorbidities 6.7; mean number of medications 7.1, mean clinical frailty score 7.3). Four (19\%) patients who had capacity for medical decisions. No residents declined to participate or dropped out of the project, i.e. through moving out of the $\mathrm{RH}$.

\section{CGA}

All 21 residents had CGA with psychiatric input and 16 (76.2\%) had dementia with evidence of BPSD at review. For the residents reviewed there was a mean reduction in admissions of 0.9 per person per year (see Table 2). Acute hospital admission costs for the whole home were reduced by $£ 6025$ during the year of intervention compared to the previous year. 
Table 2 Data outcomes

\begin{tabular}{|c|c|c|c|}
\hline & \multicolumn{2}{|l|}{ Cycle 1} & \multirow{2}{*}{$\begin{array}{l}\text { Cycle } 2 \\
\text { Care Home } 3\end{array}$} \\
\hline & Care Home 1 & Care Home 2 & \\
\hline Presenting complaints & $\begin{array}{l}\text { Stealing other residents'food in } \\
\text { context of dementia } \\
\text { Worsened cough and breathless- } \\
\text { ness } \\
\text { Cognitive decline and refusal of } \\
\text { medications including warfarin } \\
\text { Aggression and paranoia } \\
\text { Breathlessness and ankle swelling } \\
\text { Weight loss, day time drowsiness } \\
\text { Uncommunicative, decline in } \\
\text { mobility, decline in oral intake } \\
\text { Pain and poor mobility } \\
\text { Falls }\end{array}$ & $\begin{array}{l}\text { Sleeping in chair, leg pain and } \\
\text { swelling } \\
\text { Anxiety, agitation } \\
\text { Recurrent UTI, generally unwell and } \\
\text { has been in bed for a no. of weeks } \\
\text { Rash, hallucinations and delusions }\end{array}$ & $\begin{array}{l}\text { Weight loss } \\
\text { Difficulty breathing } \\
\text { Challenging behaviour } \\
\text { Swollen legs } \\
\text { Refusing medication } \\
\text { General decline possible depression } \\
\text { Reduced oral intake } \\
\text { Reduced mobility } \\
\text { Low mood, insomnia } \\
\text { Slowing and movement disorder } \\
\text { Falls } \\
\text { Depression in context of dementia } \\
\text { New patient needing CGA } \\
\text { Loose stool, anaemia }\end{array}$ \\
\hline Number of GCA reviews held & 9 & 4 & 21 \\
\hline $\begin{array}{l}\text { Mean change in number of medica- } \\
\text { tions (range) }\end{array}$ & $\begin{array}{l}-1.4 \\
(-3 \text { to }+1)\end{array}$ & $\begin{array}{l}-0.3 \\
(-1 \text { to } 0)\end{array}$ & $\begin{array}{l}-2.1 \\
(-18 \text { to }+1)\end{array}$ \\
\hline Change in BPSD (staff report) & $3 / 3$ improved & $\begin{array}{l}1 / 4 \text { improved } \\
3 / 4 \text { no different }\end{array}$ & Data not collected in this cycle \\
\hline Change in BPSD (family report) & $3 / 3$ improved & $\begin{array}{l}2 / 4 \text { improved } \\
2 / 4 \text { no different }\end{array}$ & Data not collected in this cycle \\
\hline $\begin{array}{l}\text { Number of reviews attended by } \\
\text { relatives } \\
\text { (\% of total participating residents) }\end{array}$ & $\begin{array}{l}1 \\
(11.1 \%)\end{array}$ & $\begin{array}{l}0 \\
(0 \%)\end{array}$ & $\begin{array}{l}1 \\
(4.8 \%)\end{array}$ \\
\hline $\begin{array}{l}\text { Number of residents with ACP initi- } \\
\text { ated or reviewed } \\
\text { (\% of total participating residents) }\end{array}$ & $\begin{array}{l}7 \\
(77.8 \%)\end{array}$ & $\begin{array}{l}3 \\
(75 \%)\end{array}$ & $\begin{array}{l}16 \\
(76.2 \%)\end{array}$ \\
\hline $\begin{array}{l}\text { Number of DNAR forms completed } \\
\text { or reviewed pre- and post- MDT (\% } \\
\text { of total participating residents) }\end{array}$ & $\begin{array}{l}6 \text { newly initiated } \\
(66.7 \%)\end{array}$ & $\begin{array}{l}2 \text { newly initiated } \\
(50.0 \%)\end{array}$ & $\begin{array}{l}\text { Pre-MDT = } 4(19 \%) \\
\text { Post-MDT }=19(90.5 \%)\end{array}$ \\
\hline $\begin{array}{l}\text { Number of patients with Coordinate } \\
\text { My Care record created (\% of total } \\
\text { participating residents) }\end{array}$ & $\begin{array}{l}0 \\
(0 \%)\end{array}$ & $\begin{array}{l}0 \\
(0 \%)\end{array}$ & $\begin{array}{l}8 \\
(38.1 \%)\end{array}$ \\
\hline Project period (months) & 7 & 3 & 10 \\
\hline $\begin{array}{l}\text { Actual number of admissions to } \\
\text { hospital during the project period } \\
\text { in intervention residents (no. per } \\
\text { month) }\end{array}$ & $1(0.16)$ & $0(0.0)$ & $0(0.0)$ \\
\hline $\begin{array}{l}\text { Number of admissions among } \\
\text { participating residents in } 12 \text { months } \\
\text { prior to reviews (mean per person } \\
\text { over } 12 \text { months) }\end{array}$ & Data not collected in this cycle & Data not collected in this cycle & $25(1.19)$ \\
\hline $\begin{array}{l}\text { Number of admissions among } \\
\text { participating residents in } 12 \text { months } \\
\text { post review (mean per person over } \\
12 \text { months) }\end{array}$ & Data not collected in this cycle & Data not collected in this cycle & $6(0.29)$ \\
\hline $\begin{array}{l}\text { Reduction of admissions among } \\
\text { participating residents over } 1 \text { year } \\
\text { (mean per person over } 12 \text { months) }\end{array}$ & Data not collected in this cycle & Data not collected in this cycle & $19(0.9)$ \\
\hline $\begin{array}{l}\text { Costs of hospital admissions for the } \\
\text { whole care home }\end{array}$ & Data not collected in this cycle & Data not collected in this cycle & $\begin{array}{l}12 \text { months prior to intervention } \\
£ 55,678 \\
\text { During year of intervention } \\
£ 49,653\end{array}$ \\
\hline Number of educational sessions & 5 & 2 & 9 \\
\hline
\end{tabular}


Table 2 (continued)

\begin{tabular}{|c|c|c|c|}
\hline & \multicolumn{2}{|l|}{ Cycle 1} & \multirow{2}{*}{$\begin{array}{l}\text { Cycle } 2 \\
\text { Care Home } 3\end{array}$} \\
\hline & Care Home 1 & Care Home 2 & \\
\hline $\begin{array}{l}\text { Topics of half hour educational } \\
\text { sessions }\end{array}$ & $\begin{array}{l}\text { Polypharmacy and medication } \\
\text { errors } \\
\text { Challenging behaviour in dementia } \\
\text { Nutrition Pain in dementia } \\
\text { Difficult ACP discussions }\end{array}$ & $\begin{array}{l}\text { Dementia pre-diagnosis counselling } \\
\text { Cardiovascular complications in } \\
\text { geriatrics }\end{array}$ & $\begin{array}{l}\text { Skin care in the older patient } \\
\text { Advance care planning } \\
\text { Nutrition and weight loss } \\
\text { Morbidity and mortality meeting } \\
\text { End of life in the care home } \\
\text { Old age psychiatry } \\
\text { Behavioural symptom management } \\
\text { Rationalisation of medications } \\
\text { Communication between primary } \\
\text { and secondary care }\end{array}$ \\
\hline
\end{tabular}

\section{Polypharmacy}

All 21 residents had a medication review with a mean reduction of -2.1 medications per resident.

\section{End-of-life care plans}

All 21 residents had resuscitation status reviewed and ACPs were initiated or reviewed for 16 (76.2\%) residents with the input from family where appropriate. An independent mental capacity advocate was needed for one resident. There were eight $(38.1 \%)$ residents with a new care plan created on $\mathrm{CMC}$, previously no residents had a CMC record.

\section{MDT feedback}

The members of the MDT all strongly agreed that they had benefited from collaborative working and learning as part of an MDT with $100 \%$ agreeing their confidence had grown in managing residents with psychological and behavioural problems, deprescribing medications and end of life discussions. All members of the MDT agreed the project had improved their understanding of primary and secondary care systems. Feedback comments included "useful to learn from other specialties", "most enjoyed understanding roles and responsibilities of everyone involved in the care of a resident," "I enjoyed bridging the gap between primary, secondary and psychiatric care". Staff comments from feedback questionnaires commented feeling "much more supported in the care home with the presence of the MDT," and finding it "easier to raise any problems the residents may be having as the team are more accessible."

\section{Discussion}

Our objective was to improve multidisciplinary care in RHs, specifically focussing on CGA, medication burden, end-of-life care planning and team education. Our detailed MDT assessment of 34 residents from three $\mathrm{RHs}$ reduced prescribed medications and acute hospital admissions and thus NHS costs. We increased the completion of DNACPR forms and our educational sessions received positive feedback.

CGA improves outcomes for older people in the community, hospital setting and long-term facilities [22-24] but is not routinely conducted in RHs [25].

We implemented our model specifically in RHs to deliver CGA with input from GP, geriatricians, psychiatrist, pharmacist, RH staff/ managers and family members when available. We did not have direct access to therapists, social workers and voluntary staff but the GP liaised with these services when needed. Psychiatric input was essential; over $75 \%$ of residents had dementia and a high proportion experienced BPSD. Other initiatives have also found psychiatric support vital. In Camden and Islington the MDT has actively focused on mental wellbeing with psychology resources and activity coordinators, increasing knowledge, skills and staff support resulting in fewer hospital admissions and shorter lengths of stay [26]. Our project reflects similar ongoing work in the UK such as the Proactive Healthcare of Older People in Care Homes (PEACH) protocol which uses a quality improvement collaborative (QIC) intervention to improve the delivery of CGA in care homes. The PEACH intervention team comprises a GP, social care staff, nursing staff, therapists, geriatricians, voluntary staff, pharmacists, dementia specialists, care home workers/mangers and members of the public [27]. Relational working between the care home and external services is key to successful healthcare delivery in this setting [28].

Our MDT approach resulted in fewer emergency admissions and reduced medication burden. Staff reported feeling more supported and were more proactive in bringing issues to our attention. The educational sessions were open to all staff. Our intervention may have had wider impact across the $\mathrm{RH}$ as there was a reduction in hospital admission costs across the whole home.

There is little literature on addressing polypharmacy in RHs where residents are particularly vulnerable to inappropriate prescribing [29]. One systematic review 
showed that MDT meetings, educational interventions, particularly face-to-face education improved prescribing quality [30]. Our intervention facilitated MDT discussions and educational sessions around polypharmacy. Specialist pharmaceutical input also helped to reduce medications prescribed, potentially reducing costs.

Care homes (including RHs) will become the commonest place of death over the next 20 years [31]. Education, particularly peer-training and inter-professional collaboration are potentially effective mechanisms for improving end-of-life care, although education for care home staff with a high turn-over would need to be ongoing to have a sustainable impact [32]. We dedicated 3 of 16 education sessions to end-of-life care. We had multiple discussions as an MDT around end-of-life for residents enabling the development of patient-centred care plans and improved group knowledge and experience [33]. As a result of the project one GP practice to set up an 'ACP clinic'. Within both cycles, most residents had a DNACPR form completed. In cycle 2, we used an online electronic system (Coordinate My Care) to share care plans with GPs, secondary care and the Ambulance Service.

There are limitations to the model developed. Ideally MDT participants should not change however this is inevitable when using specialist trainees who regularly rotate. The presence of the same GP lead, pharmacist and $\mathrm{RH}$ staff facilitated continuity. It is important when delivering CGA as part of an MDT that there is strategic collaboration between organisations providing team members, to ensure effective MDT functioning [22]. For sustainability, trainees require protected time away from regular duties. With multiple RHs, more trainees would be required, drawing resources away from secondary care. Standardised proformas to facilitate CGA would have reduced variability and improved outcome monitoring. In addition, the MDT did not include therapists or social workers who could add considerable value. Systematic processes for screening residents in need of review such as medication burden or hospital admissions, may be more effective. Reducing acute admissions shifts the burden of care onto the RH, i.e. people who die there may have previously gone to hospital, nursing home or hospice creating increased emotional burden on staff.

We only saw a proportion of residents and would need more sessions to review all. Few family members could attend, which could have led to underrepresentation of patients' values and preferences. With more organisation, families could be invited earlier saving GPs time in following up with them. Data gathered regarding patient reviews and staff feedback differed between cycles as the project developed, making it harder to compare outcomes. We took a pragmatic approach to data collection but there are some limitations to this for example we only counted medications but did not look at groups and types of medications. This quality improvement project was set across three care homes so may not be generalisable to other settings.

Whilst this project was running there were widespread changes in policy, for example the primary care networks (PCN) UK national rollout in 2020 which ensured that every care home is now supported by an MDT by their PCN. Our project aligns with this change in policy as we have shown the benefits of the MDT working within the care home. As well as policy changes there are other emerging studies in this field such as the GRAPE study which will be looking at how GPs are involved in initiatives to improve services and care within the care home setting [34].

The $\mathrm{EHCH}$ framework highlights variable access for care home residents to NHS services [16] but does not specifically mention mental health. Our project supports the Royal College of Psychiatrists report on delivering the Long-Term Plan advocating mental health input as central to care home services [35]. The BGS policy calls for access to CGA, personalised care plans and follow-up for all older people with frailty, dementia, complex and long-term conditions. Our intervention provides a mechanism to deliver on these policies, creating an opportunity for shared learning and enabling residents to receive more specialist care.

\section{Conclusion}

This was an effective multi-disciplinary project which facilitated CGA within the RH setting whilst focussing on reducing polypharmacy and improving end-of-life care. This had a perceived impact on both physical and mental health of residents. The MDT were able to benefit from the shared learning opportunities and improved interprofessional relationships. This project demonstrates a sustainable model which could be applied to other RHs.

\section{Abbreviations}

RHs: Residential Homes; ACP: Advance care planning; EHCH : Enhanced Health in Care Homes; NHS : National Health Service; MDT: Multi-disciplinary team; BGS: British Geriatrics Society; CGA : Comprehensive Geriatric Assessment; GP : General Practitioner; CQC: Care Quality Commission; HEE: Health Education England; UCLP: University College London Partners; BPSD: Behavioural and psychological symptoms of dementia; DNACPR: Do Not Attempt Cardio-Pulmonary Resuscitation.; CMC: Coordinate My Care; PEACH: Proactive Healthcare of Older People in Care Homes; QIC : Quality improvement collaborative; PCN: Primary Care Network.

\section{Acknowledgements}

Dr. Anita Patel, GP, St Andrews Medical Practice for coordination of the pilot project.

Dr. Ilozue Ogechukwu, GP, Brunswick Park Medical Centre for assistance in coordination of the project. 


\section{Authors' contributions}

$\mathrm{AS}$ and $\mathrm{HH}$ conceived and developed the study. They orchestrated collection of data and wrote the paper. EG was involved in development and coordination of the intervention and made substantial contributions to data collection. ELS assisted with writing of the paper and approved the final version. The author(s) read and approved the final manuscript.

\section{Funding}

.Elizabeth L. Sampson was supported by Marie Curie core grant (number MCCC-FCO-16-U).

\section{Availability of data and materials}

The datasets used and/or analysed during the current study available from the corresponding author on reasonable request.

\section{Declarations}

\section{Ethics approval and consent to participate}

Under UK 'Governance Arrangements for Research Ethics Committees', ethical research committee review is not required for service evaluation or research which elicits the views, experiences and knowledge of healthcare professionals. This project would qualify as a service evaluation with NHS staff, recruited as research participants by virtue of their professional roles and the requirement for ongoing professional development. This does not require ethical review from an established NHS research ethics committee.

\section{Consent for publication}

Not applicable.

\section{Competing interests}

I declare that the authors have no competing interests as defined by BMC, or other interests that might be perceived to influence the results and/or discussion reported in this paper.

\section{Author details}

${ }^{1}$ Barnet Hospital, Wellhouse Lane, Barnet EN5 3DJ, UK. ${ }^{2}$ Barnet Enfield and Haringey Mental Health Trust, North Middlesex University Hospital, Sterling Way, London N18 1QX, UK. ${ }^{3}$ Brunswick Park Medical Centre, Brunswick Park Road, London N11 1EY, UK. ${ }^{4}$ Marie Curie Palliative Care Research Department, Division of Psychiatry, UCL, 6th Floor. Wing B. Maple House, 149 Tottenham Court Road, London W1T 7NF, UK.

Received: 18 January 2021 Accepted: 13 December 2021

Published online: 12 January 2022

\section{References}

1. William Laing. Care homes for Older People market analysis and projections. Laing Buisson survey 2016/7. https://www.laingbuissonevents. com/wp-content/uploads/2017/05/William-COP.pdf. Accessed Jan 2021.

2. Baylis, A. and Perks-Baker, S. Enhanced health in care homes Learning from experiences so far 2017. https://www.kingsfund.org.uk/sites/defau It/files/2017-11/Enhanced_health_care_homes_Kings_Fund_Decem ber_2017.pdf Accessed: Jan 2021.

3. Smith P, Sherlaw-Johnson C, Ariti C, Bardsley M. Focus on: hospital admissions from care homes. Nuffield Trust 2015. https://www.health.org.uk/ sites/default/files/QualityWatch_FocusOnHospitalAdmissionsFromC areHomes_appendices.pdf. Accessed Jan 2021.

4. Gordon A, Franklin M, Bradshaw L, Logan P, Elliott R, Gladman J. Health status of UK care home residents: a cohort study. Age Ageing. 2014:43(1):97-103.

5. British Geriatrics Society. Quest for Quality 2011. https://www.bgs.org.uk/ sites/default/files/content/attachment/2019-08-27/quest_quality_care_ homes.pdf. Accessed Jan 2021.

6. Barber N, Alldred D, Raynor DK, Dickinson R, Garfield S, Jesson B, et al. Care homes' use of medicines study: prevelance, causes and potential harm of medication errors in care homes for older people. Quality and Safety in Health Care. 2009;18:341-6.
7. Sampson EL, Candy B, Davis S, Gola AB, Harrington J, King M, et al. Living and dying with advanced dementia: a prospective cohort study of symptoms, service use and care at the end of life. Palliat Med. 2018;32(3):668-81.

8. Matthews FE, Arthur A, Barnes LE, Bond J, Jagger C, Robinson L, et al. A two-decade comparison of prevalence of dementia in individuals aged 65 years and older from three geographical areas of England: results of the Cognitive Function and Ageing Study I and II. Lancet (London, England). 2013:382:1405-12.

9. NHS England. The NHS Long Term Plan (2019) www.longtermplan.nhs.uk Accessed Jan 2021.

10. The King's Fund. Older people and emergency bed use: Exploring variation. 2012. Imison C, Thompson R, Poteliakhoff E https://wwwkingsfu ndorguk/publications/older-people-and-emergency-bed-use Accessed Jan 2021

11. The King's Fund. Enhanced Health Care in Homes, learning from experiences so far. 2017. https://www.kingsfund.org.uk/sites/default/files/201711/Enhanced_health_care_homes_Kings_Fund_December_2017.pdf Accessed Jan 2021.

12. Parker SG, Downes T, Godfrey M, Matthews R, Martin FC. Age and ageing introduced a new category of paper: healthcare improvement science. Age Ageing. 2019;48:178-84.

13. Institute of Medicine. Crossing the quality chasm: a new health system for the 21st century. Washington, DC: Institute of Medicine; 2001

14. Hancock J, Matthews J, Ukoumunne OC, Lang I, Somerfield D, Wenman J, et al. Variation in ambulance call rates for care homes in Torbay. UK Health Soc Care Community. 2017:25:932-7.

15. Rothera I, Jones R, Harwood R, Avery A, White J. General practitioner contacts with older residents in nursing and residential homes. Eur J Gen Pract. 2003;9(4):141-2.

16. The Framework for Enhanced Health in Care Homes, Version 2 March 2020. https://www.england.nhs.uk/wp-content/uploads/2020/03/theframework-for-enhanced-health-in-care-homes-v2-0.pdf. Accessed Aug 2021.

17. Masnoon N, Shakib S, Kalisch-Ellett L, Caughey GE. What is polypharmacy? A systematic review of definitions. BMC Geriatr. 2017;17:230.

18. Church S, Rogers E, Rockwood K, Theou O. A scoping review of the clinical frailty scale. BMC Geriatr. 2020;20:393.

19. NHS Digital Health Resource Groups (HRGs). https://digital.nhs.uk/dataand-information/information-standards/information-standards-anddata-collections-including-extractions/publications-and-notifications/ standards-and-collections/isb-0070-healthcare-resource-groups-hrgs. Accessed August 2021.

20. NHS Mental Capacity Act. https://www.nhs.uk/conditions/social-careand-support-guide/making-decisions-for-someone-else/mental-capac ity-act/ Accessed August 2021.

21. STOPP/START criteria for potentially inappropriate prescribing in older people: version 2. O'Mahony D, O'Sullivan D, Byrne S, O'Connor MN, Ryan C, Gallagher P. Age and Ageing 2015;44(2):213-8.

22. Chadborn NH, Goodman C, Zubair M, Sousa L, Gladman JRF, Dening T, et al. Role of comprehensive geriatric assessment in healthcare of older people in UK care homes: realist review. BMJ Open. 2019;9(4):e026921.

23. Ellis $G$, Whitehead MA, Robinson D, et al. Comprehensive geriatric assessment for older adults admitted to hospital: meta-analysis of randomised controlled trials. BMJ. 2011;343:d6553.

24. Panza F, Solfrizzi V, Lozupone M, Barulli MR, D’Urso F, Stallone R, et al. An Old Challenge with New Promises: A Systematic Review on Comprehensive Geriatric Assessment in Long-Term Care Facilities. Rejuvenation Res. 2018;21(1):3-14.

25. Goodman C. Dying in care homes when advance care planning requires wraparound care. Palliat Med. 2018;32:312.

26. Tompsell A, Burns E. Depression among older people living in care homes report 2018. https://www.bgs.org.uk/sites/default/files/content/ attachment/2018-09-12/Depression\%20among\%20older\%20people\% 20living\%20in\%20care\%20homes\%20report\%202018.pdf. Accessed Jan 2021

27. Devi R, Meyer J, Banerjee J, Goodman C, Raymond J et al. Quality Improvement Collaborative Aiming for Proactive HEAlthcare of Older People in Care Homes (PEACH): A Realist Evaluation Protocol. BMJ Open, 2018;12;8(11):e023287. 
28. Goodman C, Dening T, Gordon A, Davies S, Meyer, Martin F, Gladman J, Bowman C, Victor C, Handley M, Gage H, lliffe S, Zubair M Effective health care for older people living and dying in care homes: a realist review BMC Health Services Research 2016;16:269.

29. Barber N, Alldred D, Raynor DK, Dickinson R, Garfield S, Jesson B, et al. Care homes' use of medicines study: prevelance, causes and potential harm of medication errors in care homes for older people. Quality and Safety in Health Care. 2009;18:341-6.

30. Woodford HJ, Fisher J. New horizons in deprescribing for older people. Age Ageing. 2019;48(6):768-75.

31. Bone A, Gomes B, Etkind S, Verne J, Murtagh F, Evans C, et al. What is the impact of population ageing on the future provision of end-oflife care? Population-based projection of place of death. Palliat Med. 2018;32(2):329-36.

32. Spacey A, Scammell J, Board M, Porter S. Systematic critical realist review of interventions designed to improve end-of-life care in care homes. Nurse Health Sci. 2019:1-12.

33. British Geriatrics Society. Quest for Quality British Geriatrics Society Join Working Party Inquiry into the Quality of Healthcare Support for Older People in Care Homes: A Call for Leadership, Partnership and Quality Improvement. 2011 http://www.bgs.org.uk/campaigns/carehomes/ quest quality care homes.pdf Accessed Jan 2021.

34. Gordon AL, Devi R, Williams C, et al Protocol for a realist review of General Practitioners' Role in Advancing Practice in Care Homes (GRAPE study) BMJ Open 2020;10:e036221. doi: https://doi.org/10.1136/bmjop en-2019-036221

35. Royal College of Psychiatrists. Delivering the NHS Long-Term Plan's ambition of ageing well: Old age psychiatry as a vital resource. 2019. https:// www.rcpsych.ac.uk/docs/default-source/members/faculties/old-age/oldage-fr_oa_06.pdf?sfvrsn=c19e3cab_6 Accessed Jan 2021.

\section{Publisher's Note}

Springer Nature remains neutral with regard to jurisdictional claims in published maps and institutional affiliations.
Ready to submit your research? Choose BMC and benefit from:

- fast, convenient online submission

- thorough peer review by experienced researchers in your field

- rapid publication on acceptance

- support for research data, including large and complex data types

- gold Open Access which fosters wider collaboration and increased citations

- maximum visibility for your research: over $100 \mathrm{M}$ website views per year

At BMC, research is always in progress.

Learn more biomedcentral.com/submissions 